\title{
Openness in Translators Training: a Case Study
}

Adrià Martín-Mor, Ramon Piqué i Huerta, Pilar Sánchez-Gijón Universitat Autònoma de Barcelona, Spain

\section{Introduction}

It is very common for NGOs and public institutions to turn to translation training centres to have their main digital resources translated. Whether it is a website, internal documentation or even termbases, these institutions offer translation students a training opportunity to work with real products. But since translation training is, in the end, something more than just getting a particular text translated, the success of such training will depend on establishing an appropriate training context.

In the collaborative venture presented here, the interest by both parties came from another level from the outset. This was a collaborative venture between the Servei de Publicacions (SP - Publications Service) at the Universitat Autònoma de Barcelona and the Tradumàtica research group at the same university. The SP, which manages UAB publications, decided to introduce the OJS software package as a standard for managing and publishing academic journals. OJS is a free software for managing and publishing journals developed by the PKP consortium. This software has been developed by many within the international academic community and with a focus on localisation into various languages. One of the journals currently published through this system is Revista Tradumàtica, run by the research group of the same name. The Tradumàtica research group (www.tradumatica.net) is concerned with research into translation technologies in the broad sense, ranging from the description of the analysis of the translation process from the digital perspective to translator training in these specialised professions.

\section{Choosing the Product}

The collaborative venture between SP and the Tradumàtica research group to localise PKP software into Spanish and Catalan started during the academic year 2011-2012 and has been going on ever since. OJS caught the attention of the research group for a variety of reasons:

- Specific community asset transfer. Being able to make use of the interfaces and help files of the updated versions of PKP software in the most commonly-used languages at UAB (Catalan and Spanish) would clearly foster the use of this platform by editors and potential readership alike. 
Therefore, it is an asset transfer towards the Spanish and Catalan speaking academic community.

- Localisation of FOSS software. It is important, when designing a collaborative localisation project involving students, to choose ethically correct proposals. In this respect, the localisation of PKP software means firstly promoting an initiative which facilitates free access to knowledge and, secondly, being FOSS software, its localisation does not involve students in any profit-making activity. Furthermore, as Diaz Fouces (2011: 10) puts it, "[l]a definición de un espacio profesional autónomo y digno supone no renunciar a mantener el mayor grado posible de control sobre los procesos de traducción" "The definition of an autonomous and dignified professional space implies not waiving to keeping the highest possible control over the translation processes", our translation).

- Enhancing the product. PKP software (mainly OJS and OMP) is designed to manage and publish journals and monographs. Its development is supported by researchers involved in publications of an academic nature. Along these lines, all manner of editorial processes were envisaged during its development. Nonetheless, some design solutions adopted to facilitate the localisation of the software into other languages were not deemed the most appropriate by the Tradumàtica research group. On the basis of its experience, the group proposed software design enhancements aimed at overcoming these design problems.

- Being able to promote the use of minority/ised languages. Finally, localising into Catalan also involved standardisation. Although the main user community can work with the software directly in the Spanish or in the English versions, the localisation of the software into Catalan is currently possible within a context of standardised use due to efforts in recent years to standardise Catalan in the field of technology. Furthermore, by following the most widely used guidelines for localisation (for example, as regards the use of specialised vocabulary linked to software), we also collaborate in spreading its use among the community of users (Softcatalà 2010).

\section{The Added Value of the Project}

Once it was decided that PKP was an appealing initiative for the research group, the question of how collaboration could be established was posed. One of the most visible dimensions of the Tradumàtica research group is the Tradumàtica Masters. This is an M.A. programme oriented towards preparing 
students for the professional world with company internships and an M.A. final project (TFM, from the Catalan 'Treball de Fi de Màster'), focused on mastering the translation process and the localisation of digital products. The M.A. coordinators decided to use OJS as a product which would be localised within the framework of the TFM. Students would thus be able to put into practice all the knowledge and competencies acquired during the M.A. programme through the management, translation and testing of the software, and at the same time reflect on the localisation process.

The proposal to localise PKP software within the framework of the M.A. offered advantages for the students well worth laying out. As regards our interests as a translation training centre, it offers the opportunity of providing students with real software and, at the same time, sufficient volume of work to justify all the localisation work carried out by the approximately thirty M.A. students. It allows us to manage the project through small work groups of between 3 and 5 students. For each brief, every two weeks, the students have to change task and adopt the role of project manager, translator, proofreader and tester. As this is real software, their translation might be subject to all the conditioning factors of a real localisation project in terms of processes, phases, tools, problems, etc. Furthermore, software updates provide sufficient volume for the entire group. Therefore, introducing PKP software which students could localise as part of their training meant added value to their training and the M.A. programme. Its inclusion in the form of a TFM has proven to be a good move as well, since students are able to combine it with company internships, during which they are exposed to other products and workflows.

By localising real software under real professional practice conditions, the team of researchers/teachers involved in the project had the opportunity as well to delve further into the development of a project of this nature. Although as group researchers we are continually in touch with the professional translation sector, our obligations as full-time lecturers at the UAB prevent us from being directly involved in projects such as this. Therefore, managing both the localisation project and the learning process of the students has been of major interest for the members of the teaching team involved. Real work with the most commonly-used tools, solving specific problems corresponding to phases of the process, etc., has meant total involvement by the teachers in managing and carrying out the localisation projects. For these reasons we believe that the work with PKP represents added value for the group's research members and consequently for the M.A., given that all this will be directly applied in future M.A. classes. 
In fact, following the track of the most recent professional practices allows scholars to achieve two different objectives. Firstly, as translator trainers they have the chance to test new training models that guarantee students achieve the professional competencies needed in the translation industry. Secondly, researchers are able to take advantage of these training experiences and undertake studies to come to theoretical or empirical conclusions. Studies that measure the impact of professional practices in terms of quality or productivity are of special interest for the translation industry, but equally studies that shed light on theoretical or methodological issues of particular interest to the field of Translation Studies. This approach to Translation Studies research follows Munday's statement (2008: 179): "the emergence of new technologies has transformed translation practice and is now exerting an impact on research and, as a consequence, on the theorization of translation."

The accumulative experience gained by the Tradumàtica research group teachers from managing this localisation project has clearly allowed for developing the contents and competencies which they deal with in the M.A. in the direction of an entirely professional context. We have been able to develop our teaching models and allow more room for competencies such as teamwork and self-learning skills (regarding translation tools and problem solving). The teaching angle of this experience has allowed us to tackle competencies such as those mentioned above from a more genuine and professional perspective.

This experience has also allowed us to put into practice theoretical models developed by the group's researchers concerning the development of research projects. On the basis of this experience we have been able to develop these models according to changes in the translation profession which are becoming more and more important in the professional sector, such as machine translation and post-editing, or incorporating the specific quality control parameters required of international standards. This development from a theoretical slant has been one of the major benefits of the OJS localisation project for the Tradumàtica group.

As a consequence of the evolution of theoretical models, this project has also allowed the researchers to identify new research areas of use to society. One of the aims of the entire research group is that its research implies a return for society. Sometimes, it is difficult to measure this return. Other times, this return is too specific, and it ends up becoming a transfer of assets between universities or research centres and particular sectors of society. In fact, the majority of calls for research projects nowadays are aimed at facilitating research that offers a return for society and which contributes to the economic, productive, social and cultural development of the community. 
Following this line of reasoning, it should be pointed out that participating in projects such as the PKP software localisation allows researchers to identify much more precisely the objects of study upon which public research can have an impact and which could result in a greater return for the community. A specific case in point is our community, in which we have a professional translation sector comprised of many small companies, in many cases oneperson businesses, and a significant fabric of medium-sized companies employing up to 20 staff. By identifying these research objects whose development can benefit professionals in the translation market - and, indirectly, any professional sector -, the return of our work as researchers to society is guaranteed.

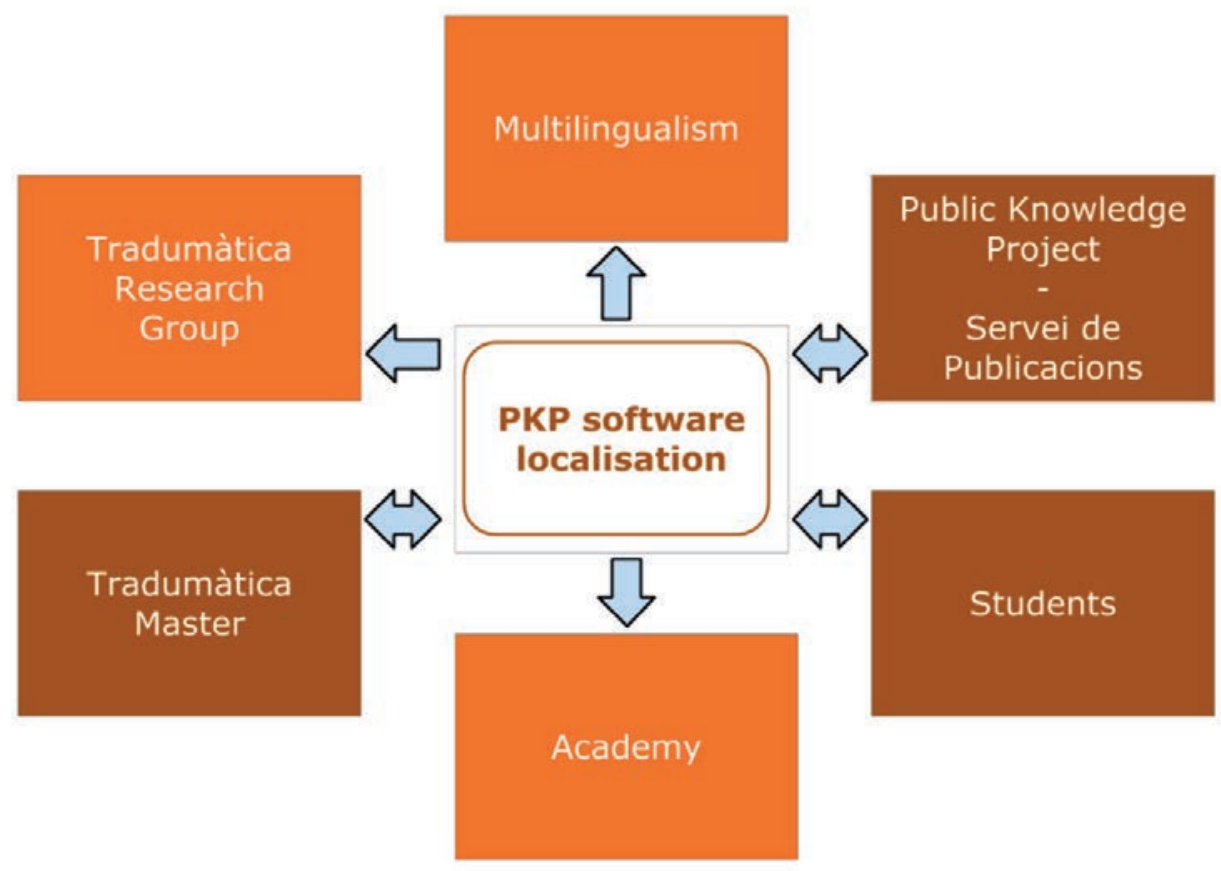

Figure 1: A multifaceted approach to PKP localisation.

\section{The Key to Success}

Despite all the advantages mentioned earlier, it also must be mentioned that the development of projects such as this are very demanding on all those involved. On the one hand, the NGO which provides the software to be localised has to act as a client in all senses. In our case, the SP at UAB has 
to take on the responsibility of preparing all the files to be localised and gives an introductory training session to the software for the students involved in the localisation of the program. More importantly, they succeed in the challenge of having to resolve terminology and language use doubts within time frames of less than 24 hours, in order to guarantee that these doubts do not become an obstacle to meeting the deadlines set for each translation brief. They even developed a tool to facilitate real testing of the software before the localisation project was finished.

From the management point of view, without a doubt one of the keys of the success of this project is that everyone is able to collaborate via a server (groups of students, coordinators and terminologists), in such a way that the resources used (essentially translation memories and terminology databases) are queried and edited simultaneously by all participants. This eases speeding up processes within each group and thus bringing forward deadlines. On the other hand, however, this requires investing time and effort in managing the task prior to the translation brief.

For the teachers/researchers who took part in this project, this requires maximum commitment. Given that they assume two roles - teachers guiding the learning process and managers of the global project - , they have to be very flexible and accommodate deadlines to the development of the project itself. By acting as managers who commission specific translations with deadlines for each work group, the turnaround time for answering queries and solving problems has to be very short. This means that the teachers must have round-the-clock access to the resources used to develop the project: tools, materials, agendas, calendars, etc., and update, modify or adapt them to whatever situation that might crop up. In addition, by also managing the learning process, they have to provide themselves with the appropriate space so that students can get to the right conclusion for each problem they encounter, guaranteeing optimal results for the training of the students. This dual role demands a high level of commitment to the project not only while it is underway but also during the preparatory and concluding phases.

\section{Dealing with Quality}

The PKP localisation project to Catalan and Spanish may be seen at the intersection between a crowdsourced translation, a professional project and a students' assignment. Despite this idiosyncratic nature, different actions were carried out in order to ensure the quality of the final product, even if - as stated above - localising a real product increases per se the students' awareness of the importance of quality (the students were informed beforehand that 
their names will appear in the contributors section of the PKP wiki at https://pkp.sfu.ca/wiki/index.php?title=Translating_OxS).

First of all, after the translators' final checks, each group carried out a crossed revision of the files translated by their own translators. Secondly, each project manager reviewed the translations delivered by its team before submitting the files and, in a subsequent stage, all translations were again cross-revised by other groups. Finally, after all groups had delivered their translations, an instance of the PKP software running on the university's servers was updated with the translated files. This allowed the students to get to know what a real testing process on localised software is like. Students were therefore asked to crawl the software, capture any kind of errors they could come across (linguistic, graphical, functional, etc.) using screen-shot software, and document the errors' nature through a classification template. This template was used to correct some linguistic issues and sent as feedback to PKP contributors.

\section{Concluding Remarks}

In this paper we have presented how openness is becoming more and more a key concept on translation following our translation project at the Tradumàtica Masters as a case in point. As mentioned earlier, we believe that FOSS software gives translation trainers an opportunity to teach how real localisation is carried out, overcoming ethical concerns and easing open access to knowledge to a greater community, thus becoming an asset transferred to society.

As this is a long-term, running project, year after year changes and modifications are included in its design. Some of the future working lines might include translation and translated software. Firstly, as for translation software, we attempt to include the latest technologies - with an eye on free software to the workflow. In this sense, some technologies like Customised Machine Translation engines or proxy-based localisation might be researched; as of the academic year 2014-2015, the XLIFF standard has been included in the project design, following our belief that, as Jiménez-Crespo (2013: 176) puts it, "basic knowledge of exchange standards" is part of the technological subcompetence. Secondly, as for the translated products, other branches of the PKP software or even other products might be explored at some point, since it can be expected that, being somewhat similar and sharing files to some extent, a number of the chains will already be translated and stored in our translation memories. 


\section{References}

Diaz Fouces, O. (2011) ¿Merece la pena introducir el software libre en la formación de traductores profesionales? Presented at Language and Translation Teaching in Faceto-Face and Distance Learning, Universitat de Vic. Vic, 8 April 2011. Available at http://www.academia.edu/3487697/_Merece_la_pena_introducir_el_software_libre_ en_la_formacion_de_traductores_profesionales [Accessed 10 March, 2015].

Kancewicz-Hoffman, N. (2008) Increasing visibility for a multifaceted Humanities research in Europe - the ERIH approach. Presented in the Conference Relevance and Impact of the Humanities, Universität Wien. Vienna, 16 December 2008. Available at http://www.qs.univie.ac.at/fileadmin/user_upload/qualitaetssicherung/Veranstaltungen/ Humanities/Praesentationen/nicht_bestaētigt/Kancewicz_Hoffmann_ERIH_impact_Vie nna_Dec08.pps [Accessed 10 March, 2015].

Kelleher, M. and Hoogland, E. (2008) Changing Publications Cultures in the Humanities. Young Researchers Forum. ESF Humanitites Spring 2011. European Science Foundation - Humanities Unit. 9-11 June 2008, Maynooth, Ireland. Available at http://www.esf.org/fileadmin/Public_documents/Publications/Changing_Publication_Cult ures_Humanities.pdf [Accessed 10 March, 2015].

Jiménez-Crespo, Miguel A. (2013) Translation and web localization. London, New York: Routledge.

Martín-Mor, A., Piqué Huerta, R. and Sánchez-Gijón, P. (forthcoming) Tradumàtica. Tecnologies de la Traducció. Vic: Eumo.

Munday, J. (2008) Introducing Translation Studies: Theories and Applications. London, New York: Routledge.

Open Journal Systems (n.d.) Public Knowledge Project. Available at https://pkp.sfu.ca/ojs/ [Accessed 10 March, 2015].

Piqué Huerta, R. and Sánchez-Gijón, P. (2013) Troubleshooting: el proyecto de formación de localizadores. VI Congreso Internacional de la AIETI: Traducimos desde el sur. Las Palmas de Gran Canaria, 23-25 January 2013.

Softcatalà (2010) Guia d'estil. Available at http://www.softcatala.org/wiki/Guia_d \%27estil/Guia_2010 [Accessed 10 March, 2015]. 